\title{
ENDOSCOPIC THIRD VENTRICULOSTOMY (ETV)
}

\author{
Dr. Mian Iftikhar ul Haq'
}

1. MBBS, MRCS (UK), MCPS,

FCPS (General Surgery)

FCPS (Training Medical Officer Neurosurgery)

Training Medical Officer

Department of Neurosurgery,

PGMI/HMC, Peshawer.

\begin{abstract}
Objective: To know the surgical outcome of endoscopic third ventriculostomy (ETV) in non communicating hydrocephalous. Design: Cross sectional descriptive study. Setting: Neurosurgery department of Hayatabad Medical Complex, Peshawar. Period: $1^{\text {st }}$ March 2010 to 1st march 2011. Materials and methods: A total of 41 patients with non-communicating hydrocephalous, irrespective of gender discrimination were included in this study. Patients below two years of age and hydrocephalus with infected CSF or hemorrhage were excluded. Hydrocephalous was diagnosed on CT scan brain. The information regarding patient demographical details, causes of hydrocephalus and complications of procedure was documented in patient's Performa. The data was analyzed by SPSS version 16. Frequency and percentage was calculated for categorical variables. Mean \pm SD was calculated for age. Results were presented as tables. Results: A total of 41 patients with non-communicating hydrocephalous were included in the study. Out of 41 patients, there were $26(63.41 \%)$ males and $15(36.58 \%)$ females. The mean age was 21 years. Etiologically tuberculous meningitis was the commonest cause of non communicating hydrocephalous. Post-operatively CSF leakage was present in $4(9.75 \%)$ patients, pseudomeningocele in $2(4.87 \%)$ patients, transient memory loss in $2(4.87 \%)$ patients and pneumocephalous in $1(2.43 \%)$ patient. Conclusions: The complications of endoscopic third ventriculostomy are transient. Those patients who meet the criteria, endoscopic third ventriculostomy offers the possibility of freedom from shunt dependency.
\end{abstract}

Key words: $\quad$ Endoscopic third ventriculostomy, complications.

Article received on:

16/05/2013

Accepted for Publication

22/10/2013

Received after proof reading:

03/02/2014

Article Citation: Mian Iftikhar ul Haq. Endoscopic third venriculostomy (ETV). Professional Med J 2014;21(1): 144-147.

\section{INTRODUCTION}

Endoscopic Third Ventriculostomy (ETV) is a onetime procedure; an opening is created in the floor of the third ventricle using an endoscope placed within the ventricular system through a burr hole. This allows the movement of cerebrospinal fluid (CSF) out of the blocked ventricular system and into the interpenducular cistern (a normal CSF space) thereby fore bypassing any obstruction. ETV is used to treat obstructive Hydrocephalus, such as aqueductal stenosis. The objective of this procedure is to normalise pressure on the brain without using a shunt. ETV is not a cure for Hydrocephalus, but rather an alternate treatment ${ }^{1,2,3}$.

Although open ventriculostomies were performed as early as 1922, they became a less common method of treating Hydrocephalus in the 1960s, with the advent of shunt systems. Despite recent advances in shunt technology and surgical techniques, however, shunts remain inadequate in many cases. Specifically, extracranial shunts are subject to complications such as blockage, infection, and over-drainage, often necessitating repeated surgical revisions ${ }^{1,4,5}$.

The ultimate goal of ETV is to render a shunt unnecessary. Although Endoscopic Third Ventriculostomy is ideally a onetime procedure, evidence suggests that some patients will require more than one surgery to maintain adequate opening and drainage $e^{3,6,7}$. The purpose of this study was to know the surgical outcome of ETV in 
patients with non-communicating hydrocephalus.

\section{MATERIALS AND METHODS}

This cross sectional descriptive study was done in neurosurgery department of Hayatabad Medical Complex, Peshawar, from 1st March 2010 to 1st March 2011. A total of 41 patients with noncommunicating hydrocephalous, irrespective of gender discrimination were included in this study. Patients below two years of age and hydrocephalus with infected CSF or hemorrhage were excluded.

Hydrocephalous was diagnosed on CT scan brain. Aesculap endoscope of 0 and 30 degree with $6 \mathrm{~mm}$ outer diameter were used. Aesculap 1chip video camera system (DAVID PV 140/PV 142 Camera) was used. The system also consisted of light source, monitor and working elements. The procedure was done under general anesthesia. The patients were placed supine with the head elevated approximately $30^{\circ}$ to minimize excessive CSF loss and pneumocephalus. A right precoronal incision was made $3 \mathrm{~cm}$ from midline and $1 \mathrm{~cm}$ medial to coronal suture. Eight $\mathrm{mm}$ burr hole was made. Endoscope was passed with free hand technique into the ventricle and irrigation was done with Ringer's solution. Endoscope negotiated into the $3^{\text {rd }}$ ventricle and the membrane bulging in front of mamillary bodies and behind the infundibular recess selected for making a hole. Fenestration in the roof of third ventricle was usually done with Fogarty catheter 6FR. Balloon inflated to widen fenestration ( $5 \mathrm{~mm}$ to $8 \mathrm{~mm}$ ). Haemosatsis was preferably secured with continuous irrigation. Scalp was sutured in one layer. Clinical Outcome of ETV was evaluated by the time of discharge and on subsequent follow up visits. Base line CT brain was done to all patients post operatively. The treatment was recorded as a success or failure. Success of the ETV was defined as partial or complete relief of symptoms. Any patient who subsequently needed VP shunting after the ETV procedure was described as having treatment failure. The information regarding patient demographical details, causes of hydrocephalus and complications of procedure was documented in patient's Performa. The data was analyzed by SPSS version 16 . Frequency and percentage was calculated for categorical variables. Mean +- SD was calculated for age. Results were presented as tables.

\section{RESULTS}

We operated 41 patients during our study period. Age ranged from 2 years to 60 years with mean age 21 years. There were $26(63.41 \%)$ male and $15(36.58 \%)$ female.

We operated only non-communicating hydrocephalous cases. Details of various etiological sources are highlighted in (Table-I).

\begin{tabular}{|l|c|c|}
\hline \multicolumn{1}{|c|}{ Cause } & No. of patients & \%age \\
\hline $\begin{array}{l}\text { Tuberculous } \\
\text { meningitis }\end{array}$ & 15 & $36.58 \%$ \\
\hline $4^{\text {th }}$ ventricular tumors & 10 & $24.39 \%$ \\
\hline Aquiductal stenosis & 09 & $21.95 \%$ \\
\hline Brain stem tumor & 05 & $12.19 \%$ \\
\hline $\begin{array}{l}\text { Cerebellar } \\
\text { haemengioblastoma }\end{array}$ & 02 & $4.87 \%$ \\
\hline
\end{tabular}

Table-l. Etiology of hydrocephalous

The procedure was successfully performed in 40(97.56\%) patients. We converted only one case into ventriculo-peritoneal shunts due to altered anatomy. The complications of third ventriculostomy were noted in nine patients (Table-II).

\begin{tabular}{|l|c|c|}
\hline \multicolumn{1}{|c|}{ Complications } & No. of patients & \%age \\
\hline CSF leak & 04 & $9.75 \%$ \\
\hline Pseudomeningocele & 02 & $4.87 \%$ \\
\hline $\begin{array}{l}\text { Transient memory } \\
\text { loss }\end{array}$ & 01 & $2.43 \%$ \\
\hline Pneumocephalus & 02 & $4.87 \%$ \\
\hline \multicolumn{2}{|c|}{ Table-II. Complications of ETV } \\
\hline \multicolumn{2}{|c|}{} \\
\hline
\end{tabular}




\section{DISCUSSION}

Ventriculoscopy was introduced in the early 1900s. Walter E. Dandy used a primitive endoscope to perform choroid plexectomy in communicating hydrocephalus. Endoscopic management of hydrocephalus was attempted in 1910 when VL L'Espinasse, an urologist, used the cystoscope to cauterize the choroid plexus ${ }^{3,5}$.

The first ETV was performed by William Mixter, an urologist, in 1923. In 1947, H. F. McNickle introduced a percutaneous method of performing third ventriculostomy that decreased the complication rate and improved the success rate $^{2,7}$. In the early 1970s, the leukotome was introduced to enlarge the perforation in third ventricle floor without an injury to the surrounding vascular structures. An improvement in the success of third ventriculostomy in recent time could be due to better patient selection; improvements in endoscope, better imaging, advanced surgical technique and instruments $s^{1,8,9}$.

We operated 35 patients during our study period. Age ranged from 2 years to 60 years with mean age 21 years. Brohi SR also reported same results ${ }^{10}$.

There were 26(63.41\%) male and 15(36.58 \%) female. Kulkami AV reported male dominancy in his study ${ }^{11}$. Baldauf $\mathrm{J}$ also reported the same result in his study ${ }^{12}$.

In our study the commonest cause of noncommunicating hydrocephalus was tuberculous meningitis i.e in 15(36.58\%) patients. Brohi SR has reported almost the same sequence of causes for hydrocephalus ${ }^{10}$.

Various studies suggests various ETV failure rates which ranges from $6 \%$ to $50 \%{ }^{13,14}$. In the present study, the procedure failed in one patient. However, we believe that conversion rate can further be decreased as the surgeons getting experienced and with improvement in endoscopic technology.

The incidence of complications with ETV has been reported ranging from $0-20 \%{ }^{15,16}$. In our study, the overall rate of complications encountered is $21.95 \%$. However there has been no permanent disability or morbidity. The commonest complication in our cases is CSF leak which occurred in $4(9.75 \%)$ patients. Brohi SR also reported the same complications ${ }^{10}$.

\section{CONCLUSIONS}

The complications of endoscopic third ventriculostomy are transient. Those patients who meet the criteria, endoscopic third ventriculostomy offers the possibility of freedom from shunt dependency.

Copyright@ 15 Sep, 2013.

\section{REFERENCES}

1. Yadav YR, Parihar V, Pande S, Namdev H, Agarwal M. Endoscopic third ventriculostomy. J Neurosci Rural Pract 2012;3:163-73.

2. Tubbs RS, Hattab EM, Loukas M, Chern JJ, Wellons M, Wellons JC, Iskandar BJ, Cohen-Gadol AA. Histological analysis of the third ventricle floor in hydrocephalic and nonhydrocephalic brains: application to neuroendocrine complications following third ventriculostomy procedures. J Neurosurg Pediatr 2012;9:178-81.

3. Tekin T, Colak A, Kutlay M, Demircan MN.Chronic subdural hematoma after endoscopic third ventriculostomy: a case report and literature review. Turk Neurosurg 2012;22:119-22.

4. Yadav YR, Parihar V, Agrawal M, Bhatele PR. Endoscopic third ventriculostomy in tubercular meningitis with hydrocephalus. Neurol India 2011;59:855-60.

5. Moorthy RK, Rajshekhar V. Endoscopic third ventriculostomy for hydrocephalus: a review of indications, outcomes, and complications. Neurol India 2011;59:848-54.

6. Woodworth GF, See A, Bettegowda C, Batra S, Jallo GI, Rigamonti D.Predictors of surgery-free outcome in adult endoscopic third ventriculostomy. World Neurosurg 2012;78:312-7.

7. Aquilina K, Pople IK, Sacree J, Carter MR, Edwards RJ.The constant flow ventricular infusion test: a simple and useful study in the diagnosis of third ventriculostomy failure. J Neurosurg 2012;116: 445-52.

8. Durnford AJ, Kirkham FJ, Mathad N, Sparrow 
OC.Endoscopic third ventriculostomy in the treatment of childhood hydrocephalus: validation of a success score that predicts longterm outcome. J Neurosurg Pediatr 2011;8:489-93.

9. Grand W, Chamczuk AJ, Leonardo J, Snyder KV. Endoscopic third ventriculostomy for hydrocephalus after perimesencephalic subarachnoid hemorrhage: initial experience in three patients. Acta Neurochir 2011;153:2049-55;

10. Brohi SR, Brohi AR, Sidiqui MA, Mughal SA, Saeed $S$. Outcome of endoscopic third ventriculostomy in hydrocephalus. JSP 2010;15:25-28.

11. Kulkarni AV, Hui S, Shams I, Donnelly R.Quality of life in obstructive hydrocephalus: endoscopic third ventriculostomy compared to cerebrospinal fluid shunt. Childs Nerv Syst 2010;26:75-9.

12. Baldauf J, Oertel J, Gaab MR, Schroeder HW. Endoscopic third ventriculostomy for occlusive hydrocephalus caused by cerebellar infarction. Neurosurgery. 2006 ;59:539-44.

13. Fukuhara T, Luciano MG, Kowalski RJ. Clinical features of third ventriculostomy failures classified by fenestration patency. Surg Neurol 2002; 58: $102-110$.

14. Mohanty A, Vasudev MK, Sampath S, Radhesh S,Sastry-Kolluri VR. Failed endoscopic third ventriculostomy in children: management options. Pediatr Neurosurg 2002; 37: 304-309.

15. Amini A, Schmidt RH: Endoscopic third ventriculostomy in a series of $\mathbf{3 6}$ adult patients. Neurosurg Focus 2006;9: 23.

16. Baykan $\mathrm{N}$, et al: Ten years of experience with pediatric neuroendoscopicthird ventriculostomy: Features and perioperative complications of 210 cases. J Anesthesiol 2005;17:33-7.

\section{PREVIOUS RELATED STUDY}

Naveed Ashraf, Fauzia Sajjad, Muhammad Akmal Azeemi, Asma Ghouri. COLLOID CYST OF THE THIRD VENTRICLE; ENDOSCOPIC EXCISION (Original) Prof Med Jour 17(1) 156-163 Jan, Feb, Mar 2010.

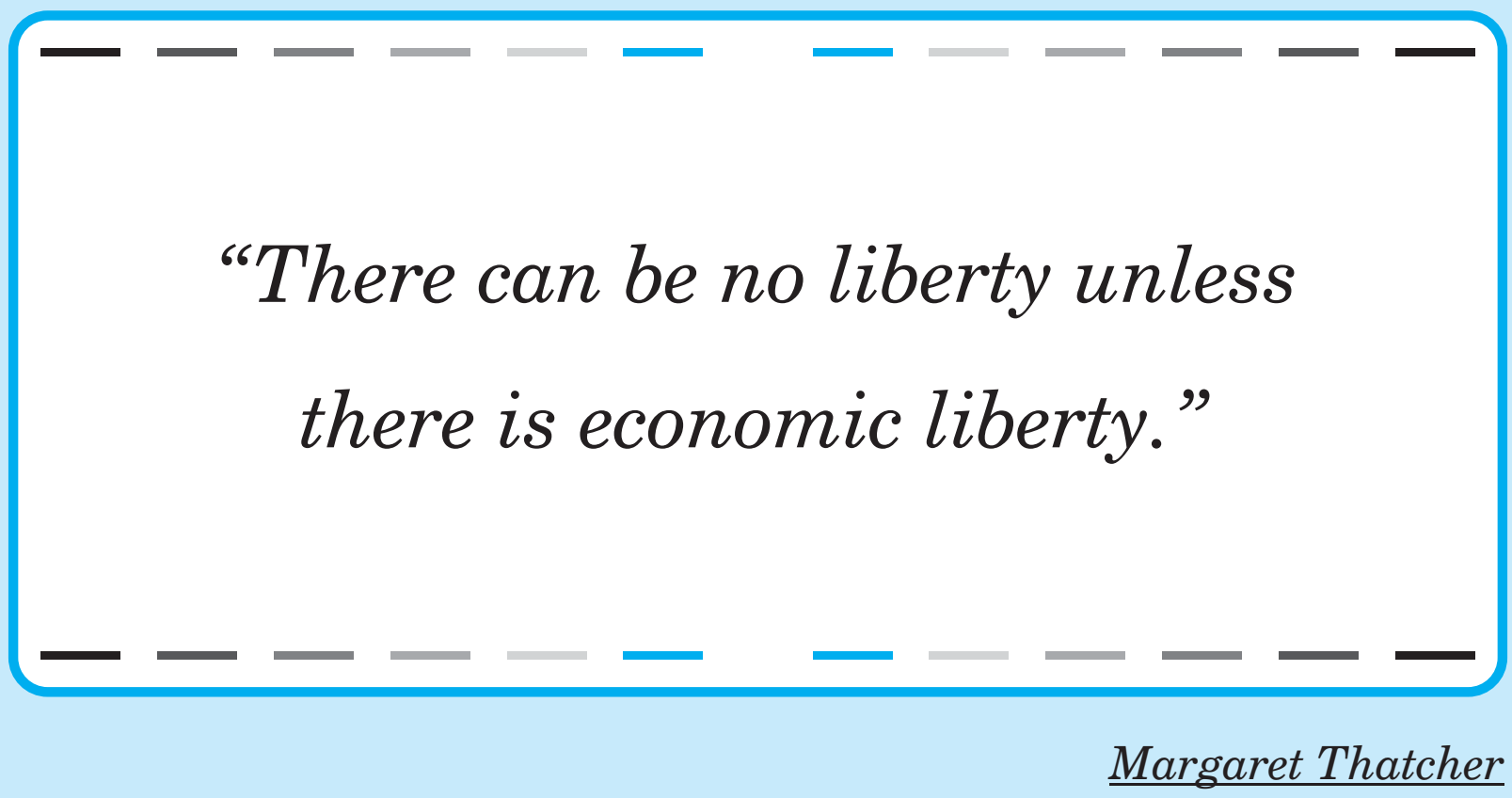

